\title{
POLÍTICAS PÚBLICAS E DESENVOLVIMENTO RURAL EM GOIÁS: análise a partir do Programa de Aquisição de Alimentos (PAA) e do Programa Nacional de Produção e Uso do Biodiesel (PNPB) ${ }^{1}$
}

\author{
POLÍTICAS PÚBLICAS Y DESARROLLO RURAL EN GOIÁS: \\ análisis a partir del Programa de Adquisición de Alimentos (PAA) y \\ del Programa Nacional de Producción y Uso de Biodiesel (PNPB)
}

\author{
Karinne de Pina Silva \\ Licenciada em Geografia pelo IESA/UFG, Goiânia-GO \\ Membro do TRAPPU (Grupo de Estudos e Pesquisas Trabalho, Território e Políticas Públicas) \\ E-mail: karinnepina28@gmail.com \\ Adriano Rodrigues de Oliveira \\ Docente dos Cursos de Graduação e Pós-graduação em Geografia do IESA/UFG, Goiânia-GO \\ Líder do TRAPPU (Grupo de Estudos e Pesquisas Trabalho, Território e Políticas Públicas) \\ E-mail: adriano.ufg@gmail.com
}

\begin{abstract}
Resumo
A pesquisa desenvolvida teve por objetivo analisar as políticas públicas de desenvolvimento rural em Goiás, ancorada em dois programas: o Programa de Aquisição de Alimentos (PAA) e o Programa Nacional de Produção e Uso do Biodiesel (PNPB). Os programas foram criados para fortalecer a agricultura camponesa e garantir um mercado consumidor por meio da formação de canais institucionais. Foi analisado os dados e informações acerca dos volumes de recursos alocados no estado de Goiás, bem como a quantidade de agricultores, associações, cooperativas contempladas e também instituições que têm sido atendidas pelos produtos oriundos da agricultura camponesa. Assim, destacou-se a forma de implementação das principais políticas públicas sendo executadas em Goiás e quais efeitos desta inserção para a autonomia da agricultura camponesa, bem como as perspectivas de desenvolvimento rural.
\end{abstract}

Palavras-chave: Políticas públicas. Desenvolvimento rural. PAA. PNPB. Goiás.

\section{Resumén}

La investigación realizada tuvo como objetivo analizar las políticas públicas para el desarrollo rural de Goiás, que se detallan en especial en los programas: el Programa de Adquisición de Alimentos (PAA) y el Programa Nacional de Producción y Uso de Biodiesel (PNPB). Destacando que los dos programas fueron creados para fortalecer la agricultura familiar y garantizar el mercado de consumo a través de canales institucionales. Aún así, el objetivo central de la investigación fue analizar y comprender su aplicación a partir de datos e información sobre el volumen de los fondos asignados en el estado de Goiás, y el número de agricultores, asociaciones, incluidas las cooperativas y también las instituciones que han cumplido los productos procedentes de la agricultura familiar. De esa forma, se destaca la aplicación de las principales políticas públicas que se implementan en el estado y los efectos de su inserción en la autonomía de la agricultura campesina, así como en las perspectivas para el desarrollo rural. 
Políticas públicas e desenvolvimento rural em Goiás:

Palabras clave: Políticas públicas. Desarrollo Rural. PAA. PNPB. Goiás.

\section{Introdução}

A pesquisa tem como objetivo central a análise das políticas públicas de desenvolvimento rural em Goiás, abordando principalmente aquelas que foram institucionalizadas a partir da década de 2000. Está circunscrita a dois programas que têm se destacado no âmbito da agricultura camponesa brasileira, um propondo a aquisição de alimentos produzidos por meio da agricultura familiar: o Programa de Aquisição de Alimentos (PAA) e o Programa Nacional de Produção e Uso do Biodiesel (PNPB), com intuito de promover a produção de biocombustíveis a partir de diferentes oleaginosas.

Esses programas foram criados visando fortalecer a produção familiar, por meio do incentivo à geração de renda, a obtenção da segurança alimentar e nutricional e a fixação do homem ao campo, tendo em vista que por meio da criação de canais institucionais de comercialização, foram sendo preenchidas uma das principais lacunas para a produção agrícola de pequena escala: as barreiras comerciais. Apesar dos limites institucionais, orçamentários e da abrangência ainda reduzida, diante do contingente representado pela a agricultura camponesa no Brasil, houve mudanças estruturais na inserção deste segmento social ao mercado consumidor.

Nessa perspectiva, obteve-se informações acerca do volume de recursos alocados no estado de Goiás, o número de agricultores, associações e cooperativas contempladas, bem como as instituições que têm sido atendidas pelos produtos recebidos da agricultura camponesa, analisando e averiguando a sua influência para a produção de alimentos com vistas à segurança e soberania alimentar (no caso do PAA).

Assim, apresenta-se alguns resultados referentes ao processo de interação entre as principais políticas públicas que têm sido implementadas no estado de Goiás e os efeitos para a autonomia e a reprodução camponesa no estado de Goiás, bem como as perspectivas de desenvolvimento rural.

A metodologia baseou-se em revisão bibliográfica em publicações especializadas acerca dos seguintes temas: políticas públicas; desenvolvimento rural; questão agrária, segurança alimentar e soberania alimentar. A análise documental esteve pautada das normativas governamentais referentes ao PAA e PNPB, bem como em relatórios técnicos e operacionais de órgãos e instituições como a Empresa Brasileira de Pesquisa 
Agropecuária (EMBRAPA), o Ministério do Desenvolvimento Agrário (MDA), a Companhia Nacional de Abastecimento (CONAB), a Agência Nacional de Petróleo, Gás Natural e Bicombustível (ANP), a Secretaria de Desenvolvimento Territorial (SDT/MDA), o Ministério de Agricultura, Pecuária e Abastecimento (MAPA) e o Instituto de Pesquisas Econômicas Aplicadas (IPEA).

Embora os dados secundários tenham sido levantados em nível estadual, o recorte territorial abrangeu o município de Ipameri, localizado na Microrregião de Catalão. No município, foram realizadas entrevistas semiestruturadas junto ao poder público local, representado pela Secretaria de Agronegócio, agricultores e os presidentes das duas cooperativas de produção familiar que atuam no Assentamento Olga Benário. A escolha deste município está relacionada à expressividade produtiva no que concerne à produção de grãos, ao mesmo tempo em que a agricultura camponesa tem constituído diversas estratégias de (re)existências, notadamente nos assentamentos de reforma agrária, em função da atuação tanto do Movimento dos Trabalhadores Rurais Sem Terra (MST), quanto da Comissão Pastoral da Terra (CPT).

O artigo está dividido em cinco partes, nas quais são apresentados uma contextualização da implementação de políticas públicas com ênfase nos dois programas PAA e PNPB, analisando-os separadamente, a sistematização das informações e dados obtidos em campo e as considerações finais.

\section{Políticas públicas e agricultura camponesa: um foco no PAA e no PNPB}

No Brasil somente a partir da década de 1990, com a criação do Programa Nacional de Fortalecimento da Agricultura Familiar (PRONAF), por meio do Decreto $\mathrm{n}^{\mathrm{o}}$ 1.946 de 28 de junho de 1996, que as políticas públicas voltadas ao rural tiveram uma abertura focada na agricultura camponesa - oficialmente designada como Agricultura Familiar. Tradicionalmente as políticas agrícolas eram circunscritas a um viés setorial e produtivista que beneficiava os grandes produtores rurais, sobretudo àqueles especializados na produção de commodities para a exportação

Parte expressiva dos produtos alimentícios no Brasil é constituída pelas compras públicas que são distribuídas e direcionadas às diferentes instituições amparadas ou administradas pelo governo. Até a década de 1990, esse mercado era dominado pelos grandes distribuidores e empresas alimentícias ligadas ao agronegócio. Esse domínio se 
consolidou ainda mais com a Lei 8.666 de 1993, ao estabelecer a obrigatoriedade do procedimento licitatório para toda contratação, aquisição, venda ou alienação em órgãos públicos e acabou por restringir o acesso dos pequenos produtores a esse mercado, conforme destaca Gonçalves (2014).

O caráter setorial e produtivista das políticas públicas agrícolas perpetuava $\mathrm{o}$ privilégio histórico dos grandes produtores e retroalimentava as exportações de matériasprimas. Por sua vez, o segmento social representado pela agricultura camponesa permanecia desassistido pelo Estado.

Com a criação do Programa de Aquisição de Alimentos (PAA), houve mudanças estruturais na inserção da agricultura camponesa aos mercados institucionais. O PAA é um programa instituído a partir do Art. 19 da Lei no 10.696 de 02 de julho de 2003 no qual o governo federal compra diretamente os alimentos dos agricultores promovendo a sua participação num mercado formalizado pela ação governamental.

Por sua vez o Programa Nacional de Produção e Consumo de Biodiesel (PNPB) foi criado no âmbito do debate internacional relacionado ao incentivo à utilização de fontes alternativas e renováveis de energia. Assim, por meio da Medida Provisória $n^{\circ} 214$ de 14 de setembro de 2004, o presidente Lula incluiu o biodiesel na matriz energética nacional, modificando leis do setor para adequar o exercício da fiscalização e da formação de políticas energéticas. Outrossim, a associação da política pública com o potencial representado pela agricultura camponesa, possibilitou a abertura de um nicho de mercado institucional com o PNBP, que promovesse a produção de uma ampla gama de matériasprimas para a produção de biodiesel.

Visando compreender a evolução e implementação dos programas PAA e PNPB em Goiás e entender seu contexto atual, torna-se relevante pontuar alguns aspectos fundantes da política pública e principalmente sua importância para o desenvolvimento rural. O conceito é complexo e polissêmico, e portanto, utilizamos como ponto de partida a definição de Secchi (2010) que define que a essência conceitual de política pública como um "problema público", ou seja, para se constituir como política pública ela precisa corresponder as demandas de um problema tido como público.

Segundo Secchi $(2010$, p. 2) " [...] alguns autores e pesquisadores defendem a abordagem estatista, enquanto outros defendem abordagens multicêntricas no que se refere ao protagonismo no estabelecimento de políticas públicas". Portanto ele possui uma abordagem multicêntrica em relação as políticas públicas, por se tratar de uma 
Políticas públicas e desenvolvimento rural em Goiás:

abordagem que enquadra ações de organizações tanto estatais como privadas, governamentais ou não-governamentais.

Teixeira (2002) por sua vez define políticas públicas como sendo “[...] diretrizes, princípios norteadores de ação do poder público; regras e procedimentos para as relações entre poder público e sociedade, mediações entre atores da sociedade e do Estado". Afirma ainda que são políticas explicitadas, sistematizadas ou formuladas em documentos (leis, programas, linhas de financiamentos) que geralmente envolvem aplicações de recursos públicos. Elaborar uma política pública significa:

[...] definir quem decide o quê, quando, com que consequências e para quem. São definições relacionadas com a natureza do regime político em que se vive, como grau de organização da sociedade civil e com a cultura política vigente. Nesse sentido, cabe distinguir "Políticas Públicas" de "Políticas Governamentais". Nem sempre "políticas governamentais" são públicas, embora sejam estatais. Para serem "públicas", é preciso considerar a quem se destinam os resultados ou benefícios, e se o seu processo de elaboração é submetido ao debate público. (TEIXEIRA, 2002, p.2, grifo do autor).

Para Teixeira (2002) "As políticas públicas visam responder a demandas, principalmente dos setores marginalizados da sociedade, considerados como vulneráveis. Essas demandas são interpretadas por aqueles que ocupam o poder, mas influenciadas por uma agenda que se cria na sociedade civil através da pressão e mobilização social." Outrossim, o autor se posiciona em prol a um debate estrutural das ações do Estado, na medida em que expressa a necessidade de que a política pública atenda efetivamente os interesses das classes sociais menos favorecidas e não sejam "pulverizadas" para setores da sociedade que detêm o capital, e via de regra, têm acesso privilegiado aos recursos repassados pelo poder público.

É necessário entender o contexto histórico que perpassa as políticas públicas voltadas ao desenvolvimento rural desde sua criação, considerando que os incentivos agrícolas já faziam parte das políticas de governo, porém favorecendo apenas uma parcela privilegiada de agricultores.

Conforme Hespanhol (1997, p. 39), “[...] no período pré 1950 não havia, propriamente, uma política agrícola global, mas sim políticas específicas que atendiam aos interesses dos segmentos mais importantes da economia agrária, tais como o 
açucareiro, o cafeeiro e o cacaueiro". Logo se entende o caráter setorial produtivista de tais políticas.

Assim como salienta Wanderley (2004) "O modelo produtivista, que realizou a modernização agrícola, é hoje profundamente questionado pelos seus efeitos perversos de ordem econômica, social e ambiental, e que afetam o conjunto da sociedade." (WANDERLEY, 2004, p. 53).

De acordo com Bianchini (2005) nas “[...] últimas décadas as políticas públicas favoreceram um modelo de agricultura não sustentável, do ponto de vista econômico, social, cultural e ambiental." Para ele, na medida em que o Estado teve uma participação ativa nesse modelo de desenvolvimento, é papel do Estado rever estes instrumentos de políticas públicas e saldar uma dívida com o conjunto da sociedade que ficou excluída dos frutos deste desenvolvimento.

Portanto, torna-se possível dizer que a construção de políticas públicas esteve historicamente ligada a atuação estatal e é nesse âmbito que se torna necessário analisar e entender qual é de fato o papel das políticas públicas voltadas para os pequenos agricultores, sabendo que no Brasil é muito recente a elaboração de políticas públicas voltadas para o agricultor familiar, sendo pensada e criada apenas na década de 1990, com a criação do Programa Nacional de Fortalecimento da Agricultura Familiar (PRONAF).

O PRONAF, é uma grande conquista que possibilita: maior democratização do crédito rural para parte dos agricultores familiares, recursos para infraestrutura no município, capacitação de técnicos e agricultores familiares, recursos para assistência técnica e extensão rural de infraestrutura, segundo (TEIXEIRA, 2002).

É importante ressaltar a participação ativa dos movimentos sociais, reivindicando melhorias no âmbito das políticas governamentais. Portanto, “[...] a experiência brasileira recente parece permitir avançar a hipótese de que as políticas públicas para a agricultura familiar funcionam mais eficiente e eficazmente ali onde os movimentos sociais são mais atuantes e os agricultores mais organizados.”. (DELGADO, 1999, p. 177). Neste contexto é que são criados os Programas de Aquisição de Alimentos (PAA) e o Programa Nacional de Produção e Uso do Biodiesel (PNPB) que se constituem como foco central da pesquisa.

Entende-se que os programas foram criados visando inserir a produção familiar no mercado consumidor, visando potencializar economicamente suas atividades produtivas, ou seja para que haja desenvolvimento efetivo é necessário ampliar a 
Políticas públicas e desenvolvimento rural em Goiás:

Karinne de Pina Silva análise a partir do Programa de Aquisição de Alimentos (PAA) e do Programa Nacional de Produção e Uso do Biodiesel (PNPB)

dimensão produtiva da agricultura camponesa de meramente para o autoconsumo para a comercialização nos mercados institucionais.

Sendo assim a agricultura camponesa possui uma alta capacidade de potencializar a economia local, partindo do pressuposto que esses produtores moram onde produzem. A conjuntura econômica deste segmento social está ligada principalmente a organização social, por meio de associações, cooperativas ou grupos informais que se unem facilitando o acesso às políticas públicas, ou seja a organização social atua diretamente na economia.

As políticas públicas para a agricultura familiar são responsabilidade do Ministério do Desenvolvimento Agrário (MDA) que afirma propiciar e promover o desenvolvimento rural sustentável, a partir da implementação das políticas púbicas voltadas ao fortalecimento da agricultura familiar, sendo assim trabalhando em quatro eixos norteadores de ações e instrumentos de suas políticas, no sentido de fundamentar as estratégias de desenvolvimento rural sustentável que são: combate à pobreza rural, segurança e soberania alimentar, sustentabilidade dos sistemas de produção, geração de renda e agregação de valor. (MDA, 2010) ${ }^{2}$.

O MDA trabalha em parceria com outros ministérios, como o Ministério do Desenvolvimento Social e Combate à Fome (MDS), Ministério da Agricultura, Pecuária e Abastecimento (MAPA), entre outros. Dentre os programas que foram criados a partir dos anos 2000 voltados para a agricultura familiar podemos citar o Programa de Aquisição de Alimentos da Agricultura Familiar (PAA), criado pela Lei n ${ }^{\circ} 10.696$, de 2 de julho de 2003, o Programa Nacional de Alimentação Escolar (PNAE), e o Programa Nacional de Produção e Uso do Biodiesel (PNPB) normatizado pela Lei no 11.097, de 13 de janeiro de 2005. (MDA, 2010)

O PAA, PNPB, PNAE, estão inseridos em um caráter recente das políticas públicas de desenvolvimento rural no Brasil com ênfase na agricultura familiar e são políticas que possuem um contexto socioeconômico estável.

Os programas PAA e PNPB são diferentes desde a concepção, enquanto o PAA prioriza a produção de alimentos, tendo o Estado como comprador o PNPB consiste na produção de biodiesel, em que o MDA por meio da Secretaria da Agricultura Familiar (SAF) participa da gestão do Programa Nacional de Produção e Uso de Biodiesel (PNPB), estimulando a produção do novo combustível e procurando apoiar a participação da agricultura familiar na sua cadeia de produção. 
Políticas públicas e desenvolvimento rural em Goiás:

Os dois programas estão ancorados numa abordagem de inclusão social, produtiva e geração de renda no campo, por isso faz-se necessária a análise e a compreensão desses programas não somente para contabilizar a produção e a renda desses camponeses no contexto do desenvolvimento rural e socioeconômico do estado, mas também para entender se de fato eles estão (re)existindo com os costumes e modo de vida com seus saberes e fazeres no campo.

\section{O Programa de Aquisição de Alimentos (PAA) no estado de Goiás}

O PAA foi criado em 2003, instituído pelo Art. 19 da Lei no .10 .696 , de 02 de julho de 2003, e está inserido no Programa Fome Zero. (Esta Lei foi alterada pela Lei ${ }^{\circ}$ 12.512, de 14 de outubro de 2011. O PAA foi ainda regulamentado por diversos decretos, o que está em vigência é o Decreto $n^{\circ} 7.775$, de 4 de julho de 2012). Seu objetivo é incentivar a agricultura familiar, compreendendo ações vinculadas à distribuição de produtos agropecuários para pessoas em situação de insegurança alimentar e à formação de estoques estratégicos. (BRASIL, 2016).

O programa foi concebido para fortalecer a agricultura familiar e visa garantir o direito básico a alimentação para pessoas que se enquadram em situação de insegurança alimentar e nutricional, além de promover a inserção do produtor familiar no mercado consumidor, sendo a Companhia Nacional de Abastecimento (CONAB) responsável pela sua operacionalização.

Outrossim, salienta-se este caráter abrangente do programa, tendo em vista que atua em duas frentes: i) combate a insegurança alimentar, por meio da oferta de alimentos em quantidade e qualidade para entidades assistenciais e/ou educacionais, e; ii) cria mercados institucionais para que os produtos agrícolas (alimentos in natura e/ou processados) assegurem um rendimento médio que atendam as expectativas dos agricultores.

Outro programa, que tem ampliado a efetividade dos mercados institucionais, voltados à agricultura familiar, bem como a oferta de alimentos para as entidades educacionais é o Programa Nacional de Alimentação Escolar (PNAE) ${ }^{3}$. Com a Lei ${ }^{\circ}$ 11.947 de 16 de junho de 2009, foi instituída a obrigatoriedade aos municípios de que ao menos 30\% do valor repassado pelo Fundo Nacional de Desenvolvimento da Educação (FNDE) por meio do PNAE seja investido na compra direta de produtos da agricultura familiar. Ou 
Políticas públicas e desenvolvimento rural em Goiás:

Karinne de Pina Silva análise a partir do Programa de Aquisição de Alimentos (PAA) e do Programa Nacional de Produção e Uso do Biodiesel (PNPB)

seja, assim como o PAA, este programa também atua em duas frentes: Segurança Alimentar e Nutricional e Formação de Mercados Institucionais voltados à agricultura camponesa.

De acordo com Ribeiro; Dias (2013), o PAA tem um papel mais amplo do que apenas inserir a produção camponesa a um mercado mais equitativo: ele passa a fazer parte da reprodução e do cotidiano. A partir do momento que passam a produzir os alimentos especificamente para o programa, o cotidiano dos agricultores vai sendo alterado conforme as demandas do programa. Tal processo, pode resultar numa sinergia, mas também pode comprometer a autonomia produtiva camponesa, por meio da alteração do seu modo de vida.

O PAA considera dois públicos beneficiários, que são: os fornecedores e os consumidores. De acordo com a Cartilha PAA (2012),

Os beneficiários fornecedores são os agricultores familiares, assentados da reforma agrária, silvicultores, aquicultores, extrativistas, pescadores artesanais, indígenas, integrantes de comunidades remanescentes de quilombos rurais e demais povos e comunidades tradicionais, que atendam aos requisitos previstos no art. $3^{\circ}$ da Lei $n^{\circ} 11.326$, de 24 de julho de 2006. Os beneficiários consumidores são os indivíduos em situação de insegurança alimentar e nutricional e aqueles atendidos pela rede socioassistencial e pelos equipamentos de alimentação e nutrição. (BRASIL, 2012, p. 4).

Segundo o Ministério do Desenvolvimento Social (MDS), o Programa de Aquisição de Alimentos (PAA) é um programa de compras do Governo Federal, que promove a organização produtiva e econômica no meio rural, o combate à pobreza extrema, o desenvolvimento local e a segurança alimentar e nutricional, os principais objetivos do programa são: fortalecer a agricultura familiar, incentivar hábitos alimentares saudáveis, bem como o fato de estimular a organização dos camponeses em associações e cooperativas, assim como salienta Oliveira (2010, p. 41);

As associações, bem como as cooperativas que ainda permanecem organizando a produção familiar - sobretudo nos assentamentos rurais, vêm se articulando como importante estratégia de reprodução. A reprodução dos produtores familiares pode ser entendida em suas múltiplas dimensões, que abrangem desde a economia, a política, o social até a cultura. 
Políticas públicas e desenvolvimento rural em Goiás:

Karinne de Pina Silva análise a partir do Programa de Aquisição de Alimentos (PAA) e do Programa Nacional de Produção e Uso do Biodiesel (PNPB)

No PAA os alimentos produzidos e comercializados são destinados para instituições públicas como escolas estaduais e municipais, creches, asilos etc., com intuito de atender grupos sociais com vulnerabilidade alimentar.

O PAA promove o acesso à alimentação e incentiva a agricultura familiar e o orçamento do programa é composto por recursos do Ministério do Desenvolvimento Social e Combate à Fome (MDS) e do Ministério do Desenvolvimento Agrário (MDA). É dividido em várias modalidades, possuindo a modalidade de compras com doação simultânea, que propicia a aquisição de alimentos para distribuição ou para formação de estoques públicos. Vale frisar que em Goiás apenas três municípios aderiram esta modalidade, sendo eles, Jussara, Jataí e Goiânia. A modalidade de apoio à formação de estoques, que tem como finalidade apoiar financeiramente a constituição de estoques de alimentos por organizações da agricultura familiar, visando agregar valor à produção e sustentação de preços. A modalidade de incentivo à produção, que possui como finalidade garantir que estados, Distrito Federal e municípios, além de órgãos federais também possam comprar alimentos da agricultura familiar, dispensando-se a licitação, facilitando às demandas regulares de consumo de alimentos e a modalidade de consumo de leitePAA e Compra Institucional.

Para ter acesso ao programa é necessário possuir a Declaração de Aptidão ao PRONAF (DAP), assim essa declaração é exercida como um instrumento institucional de identificação para o agricultor familiar acessar as políticas públicas. A operacionalização do programa é feita pela Companhia Nacional de Abastecimento (CONAB) possuindo parcerias como o município e o estado.

Tabela 1: Evolução do PAA no estado de Goiás e no Brasil - 2011 a 2016

\begin{tabular}{c|c|r|r|r}
\hline \multirow{2}{*}{ Ano } & Escala & $\mathbf{N}^{\mathbf{0}}$ de Agricultores & $\mathbf{N}^{\mathbf{0}}$ de entidades & Recursos (R\$) \\
\hline \multirow{2}{*}{2011} & Goiás & 2.266 & 1.075 & $9.899 .348,11$ \\
\cline { 2 - 5 } & Brasil & 160.011 & 25.361 & $667.325 .490,15$ \\
\hline \multirow{2}{*}{2012} & Goiás & 2.828 & 2.469 & $13.101 .182,14$ \\
\cline { 2 - 5 } & Brasil & 179.386 & 29270 & $837.823 .729,34$ \\
\hline \multirow{2}{*}{2013} & Goiás & 1.575 & 774 & $7.713 .813,11$ \\
\cline { 2 - 5 } & Brasil & 96.533 & 12.206 & $442.703 .401,85$ \\
\hline \multirow{2}{*}{2014} & Goiás & 2.624 & 985 & $16.695 .428,36$ \\
\cline { 2 - 5 } & Brasil & 112.274 & 13.054 & $573.285 .819,94$ \\
\hline \multirow{2}{*}{2015} & Goiás & 2.114 & 556 & $16.035 .444,93$ \\
\cline { 2 - 5 } & Brasil & 95.871 & 14.065 & $555.429 .848,06$ \\
\hline \multirow{2}{*}{2016} & Goiás & 0 & 447 & 0 \\
\cline { 2 - 5 } & Brasil & 78.809 & 14.772 & $418.366 .375,57$ \\
\hline
\end{tabular}

Fonte: Companhia Nacional de Abastecimento (CONAB)/ Superintendência Regional de Goiás (SUREG/GO) / Gerência de Operações (GEOPE) / Setor de Operações Comerciais (SECOM).

Orgs.: PEIXOTO. Â. M. M, 2015. Atualizado: OLIVEIRA, A. R de, 2018. 
Na tabela 1, é possível visualizar a evolução do Programa de Aquisição de Alimentos no estado de Goiás e no Brasil, no período de 2011 a 2016. Pelos dados apresentados, é possível constatar o ápice do Programa em 2012, na escala nacional, e em 2014, no estado de Goiás. A partir de então os recursos destinados ao PAA começam a declinar sistematicamente por dois motivos principais. O primeiro está circunscrito à Operação "Agro Fantasma” da Polícia Federal no estado do Paraná, que colocou sob suspeição um conjunto de agricultores vinculados à Associação dos Grupos de Agricultura Ecológica São Francisco de Assim no município de Irati. Conforme informações do Jornal Brasil de Fato (2017), tal operação, resultou na criminalização infundada dos agricultores e deu início a derrocada do Programa de Aquisição de Alimentos em nível nacional. Posteriormente, a partir de 2016, com o impeachment da presidenta Dilma Rousseff e ascensão de Michel Temer ao poder, não somente o PAA, mas outros programas vinculados às políticas territoriais foram sendo enfraquecidos.

É importante ressaltar que dos 246 municípios goianos, 87 municípios participaram ou se beneficiaram do programa, o que equivale a $44 \%$ de abrangência do PAA no estado em 2014. Embora tenha havido uma oscilação negativa desta cobertura estadual, considerando que em 2011 houve a participação de 160 municípios (65\%), a dotação orçamentária cresceu sistematicamente chegando ao montante de $\mathrm{R} \$ 13.976 .381,82$, o que equivale a um acréscimo percentual de $1774 \%$ no período de 2005 a 2014. Neste mesmo período houve um aumento de $651 \%$ no número de produtores atendidos e o número de entidades foi de $24 \%$. Na análise global dos dados apresentados da tabela 1, pode-se salientar que o PAA - juntamente com outras políticas públicas atreladas ao campo como o PNAE, PRONAF e Previdência Rural - pode ter redundado em mudanças efetivas e estruturais no desenvolvimento rural, na medida em que houve uma inversão efetiva de capital nas economias locais.

A seguir nas figuras 1 e 2, os mapas demonstram um comparativo de contratos do PAA com cooperativas nos municípios goianos em 2007 e 2014, complementando as informações acerca da evolução das organizações apresentadas na Tabela 1: 
Políticas públicas e desenvolvimento rural em Goiás:

Karinne de Pina Silva análise a partir do Programa de Aquisição de Alimentos (PAA) e do Programa Nacional de Produção e Uso do Biodiesel (PNPB)

Figura 1: Localização das cooperativas com projetos do PAA aprovados em 2007 ESTADO DE GOIÁS: DADOS DE PROJETOS DO PROGRAMA DE AQUISIÇÃO DE ALIMENTOS, 2007

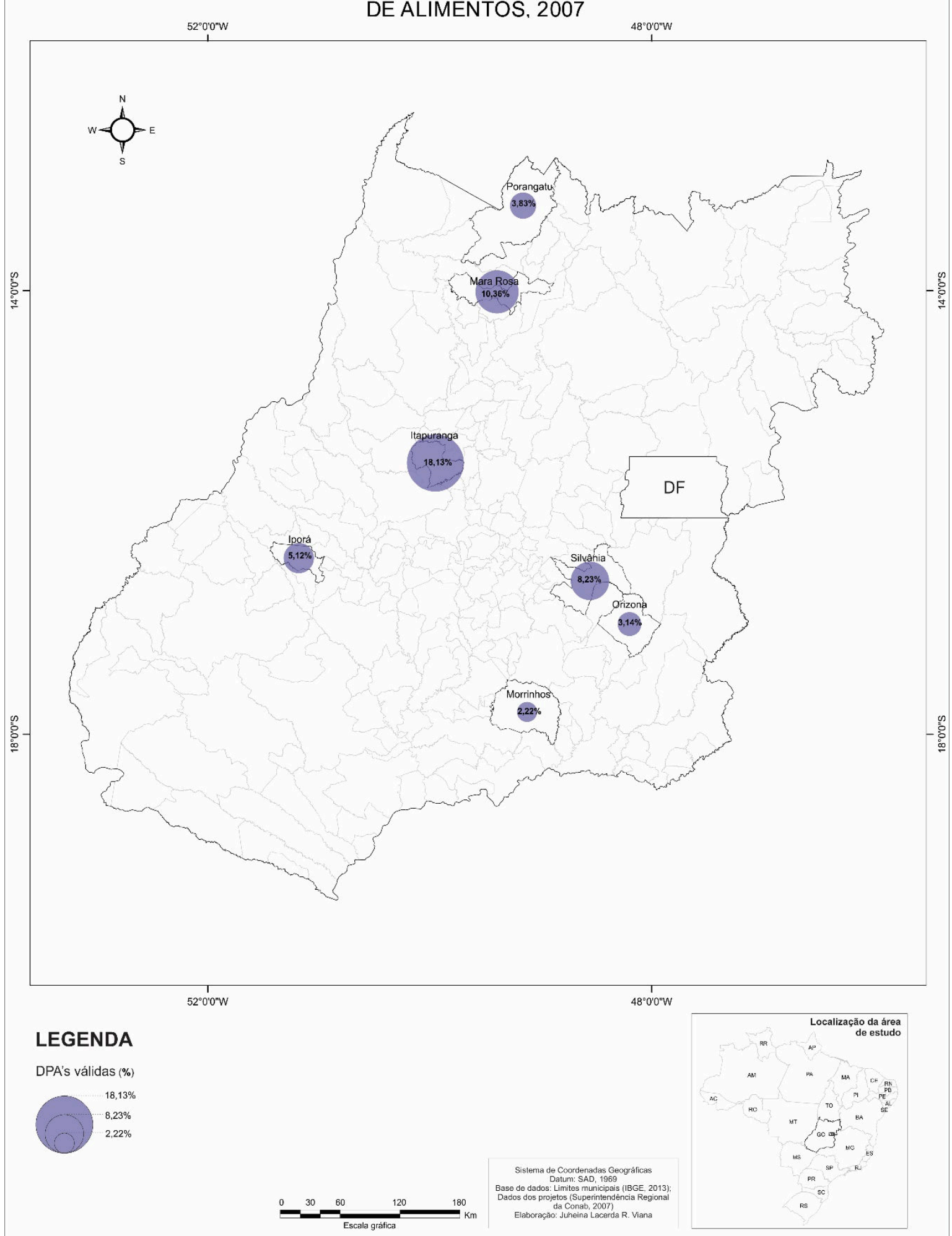

Fonte: Superintendência Regional da CONAB. 
Políticas públicas e desenvolvimento rural em Goiás:

Karinne de Pina Silva análise a partir do Programa de Aquisição de Alimentos (PAA) e do Programa Nacional de Produção e Uso do Biodiesel (PNPB)

Figura 2: Localização das cooperativas com projetos do PAA aprovados em 2007 ESTADO DE GOIÁS: DADOS DE PROJETOS DO PROGRAMA DE AQUISIÇÃO DE ALIMENTOS, 2014

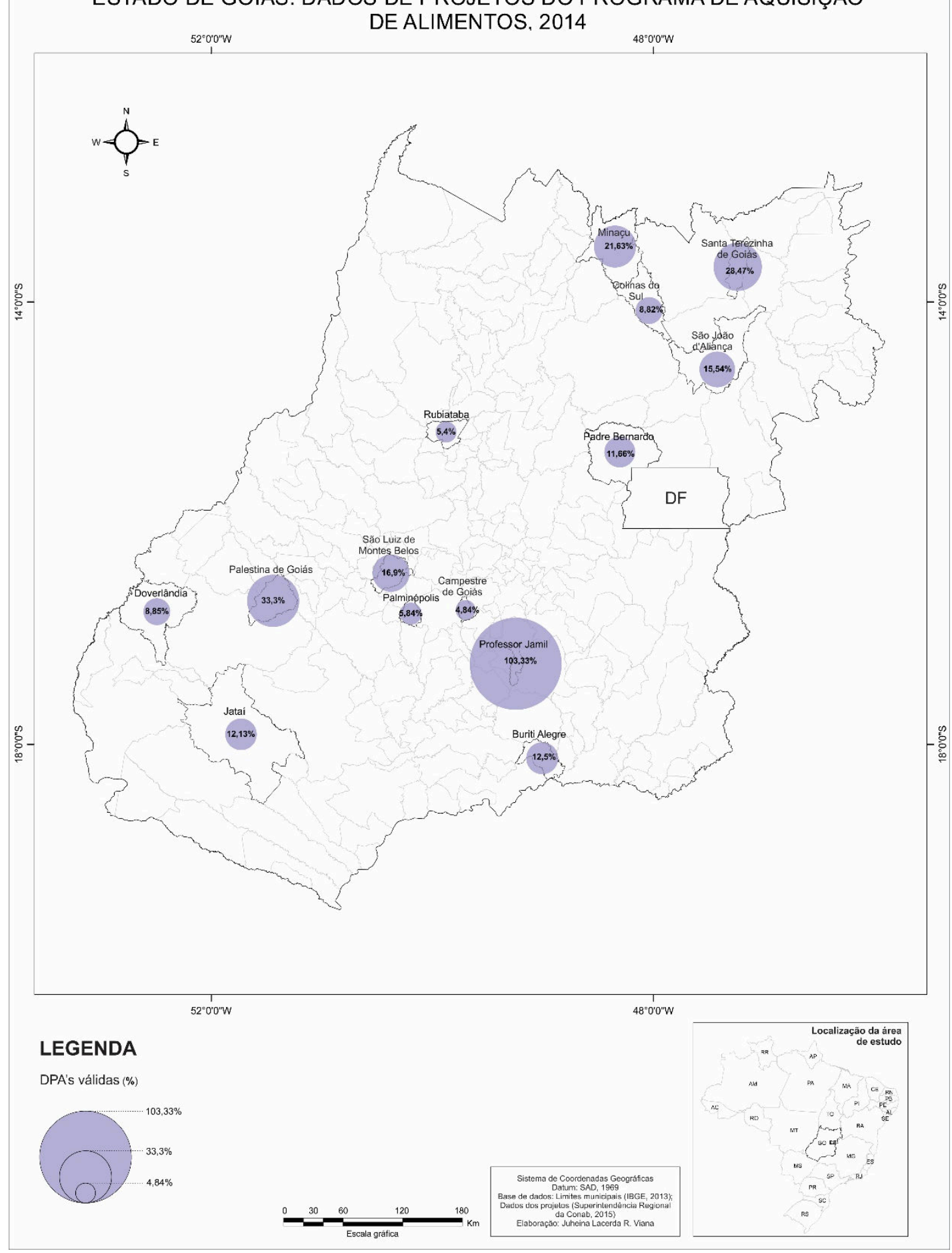

Fonte: Superintendência Regional da CONAB

As figuras 1 e 2, ilustram o percentual de Declarações de Aptidão ao PRONAF (DAP's) ${ }^{4}$ com caráter jurídico, existentes no estado de Goiás nos dois anos em destaque (2007 e 2014). Os dados demonstram a ampliação da abrangência das organizações 
Políticas públicas e desenvolvimento rural em Goiás:

coletivas que passaram a ser contempladas pelo PAA em um número maior de municípios no estado, conforme destaca Souza (2016):

[...] a partir destes números (uma informação complementar atualizada do SIM-MDA) aponta que em 2014 cinquenta empreendimentos - não especificando a respeito de serem cooperativas ou também associações-, realizaram contratos na modalidade PAA Formação de Estoque até setembro de 2014 , em um valor total de $\mathrm{R} \$ 400.000,00$, média de $\mathrm{R} \$ 50.000,00$ por empreendimento), tem-se uma noção aproximada e útil sobre a capilaridade do Programa. (p. 48)

Assim, os desdobramentos e os resultados apresentados pelo programa no estado - ainda que limitados a menos da metade dos municípios - são suficientes para assegurar a efetividade na geração de renda para a agricultura camponesa, bem como o atendimento da demanda de entidades assistenciais e educacionais, cumprindo os pressupostos da Segurança Alimentar e Nutricional, conforme veremos no próximo item, no qual será abordada a experiência empírica do município de Ipameri, localizado na MRG de Catalão ${ }^{5}$.

\section{A implantação do PAA no município de Ipameri- GO}

O município de Ipameri possui uma singularidade no contexto regional da MRG Catalão, sendo que por um lado, se destaca como segundo maior produtor de grãos, e por outro, a agricultura camponesa tem construído estratégias de (re)existências nos assentamentos de Reforma Agrária, com a presença marcante do Movimento dos Trabalhadores Rurais Sem Terra (MST) e da Comissão Pastoral da Terra (CPT). Conforme os dados preliminares do Censo Agropecuário de 2017, o município produziu 448.237 toneladas de grãos, o que equivale a 33,6\% do total regional, atrás do município de Catalão que produziu 476.564, equivalendo a 35,7\%. Em nível estadual a MRG de Catalão é responsável por 7,8\% da produção total de grãos.

Após compreender a implementação do Programa de Aquisição de Alimentos fazse necessário uma investigação que avalie seu desempenho e funcionalidade na prática junto aos principais interessados, que são os agricultores (e por consequência também podem ser caracterizados como beneficiários, embora esta seja a designação atribuída às entidades receptoras dos alimentos), que são os sujeitos principais desta pesquisa.

Nesse sentido, “[...] conhecer o contexto onde a política acontece é muito importante para entender a dinâmica política, os comportamentos dos atores e os efeitos 
Políticas públicas e desenvolvimento rural em Goiás:

das políticas públicas" (SECCHI, 2010, p. 61). Assim, entender a dinâmica espacialconcreta do PAA é o foco que daremos a seguir.

Ao estabelecer o contato com os sujeitos da pesquisa, com destaque ao poder público local, personificado pela Secretaria de Agronegócio, os camponeses bem como as lideranças das associações, é possível ressaltar uma insatisfação dos produtores beneficiados em relação a burocracia que acaba dificultando o acesso, partindo até mesmo da demora do cadastramento na Declaração de Aptidão ao Pronaf - DAP.

No município de Ipameri, a "Compra por Doação Simultânea” é a modalidade efetuada por intermédio das associações que se localizam no assentamento Olga Benário, no qual foi realizada a pesquisa empírica. O assentamento foi criado em 2005 por meio da desapropriação de uma área de 4.322 hectares realizada pelo INCRA (Instituto Nacional de Colonização e Reforma Agrária) com capacidade para assentar 81 famílias, conforme os dados do DATALUTA (2015). Desde então foram formadas duas associações, a Associação Camponesa Regional de Agricultura Familiar (ASCRAF) e a Associação dos Pequenos Produtores do Assentamento Olga Benário (ASPROAB).

A associação ASPRAOB surgiu em 2009, e segundo o seu presidente, e recentemente, foram beneficiados pelo programa "Terra Sol"6 do INCRA. Foi concedido o montante de duzentos e cinquenta mil reais, que será utilizado para ampliação da panificadora local, bem como a montagem de uma farinheira. Com a participação no PAA a associação atingiu o equivalente a 40 associados e conseguiu a aprovação o selo de inspeção sanitária regularizado pelo Serviço de Inspeção Municipal (S.I.M). Algumas imagens da panificadora da ASPRAOB podem ser observadas na figura 03.

A panificadora produz os panificados durante a cada dois dias da semana e realiza a entrega também a cada dois dias. Assim, são intercalados os dias de produção e entrega, sendo organizado da seguinte forma: a produção é realizada nas segundas e quartas feiras e a entrega nas terças e quintas-feiras. São produzidos em torno de 3.000 roscas e 3.500 pedaços de bolos. As atividades foram iniciadas com o revezamento das famílias por meio de equipes de produção de 6 a 7 pessoas. São 27 DAP's das famílias que integram o grupo responsável pela panificadora. Foram realizados dois cursos de panificação e confeitaria, desde o início das atividades em março de 2014. A construção da estrutura da panificadora foi a partir da união dos assentados, assim como a compra do veículo do tipo furgão para entregar os produtos nas entidades beneficiadas pelo PAA. 
Políticas públicas e desenvolvimento rural em Goiás:

Karinne de Pina Silva análise a partir do Programa de Aquisição de Alimentos (PAA) e do Programa Nacional de Produção e Uso do Biodiesel (PNPB)

Figura 3: Imagens das instalações da panificadora e o do processo de elaboração dos panificados da ASPRAOB no Assentamento Olga Benário, município de Ipameri-GO
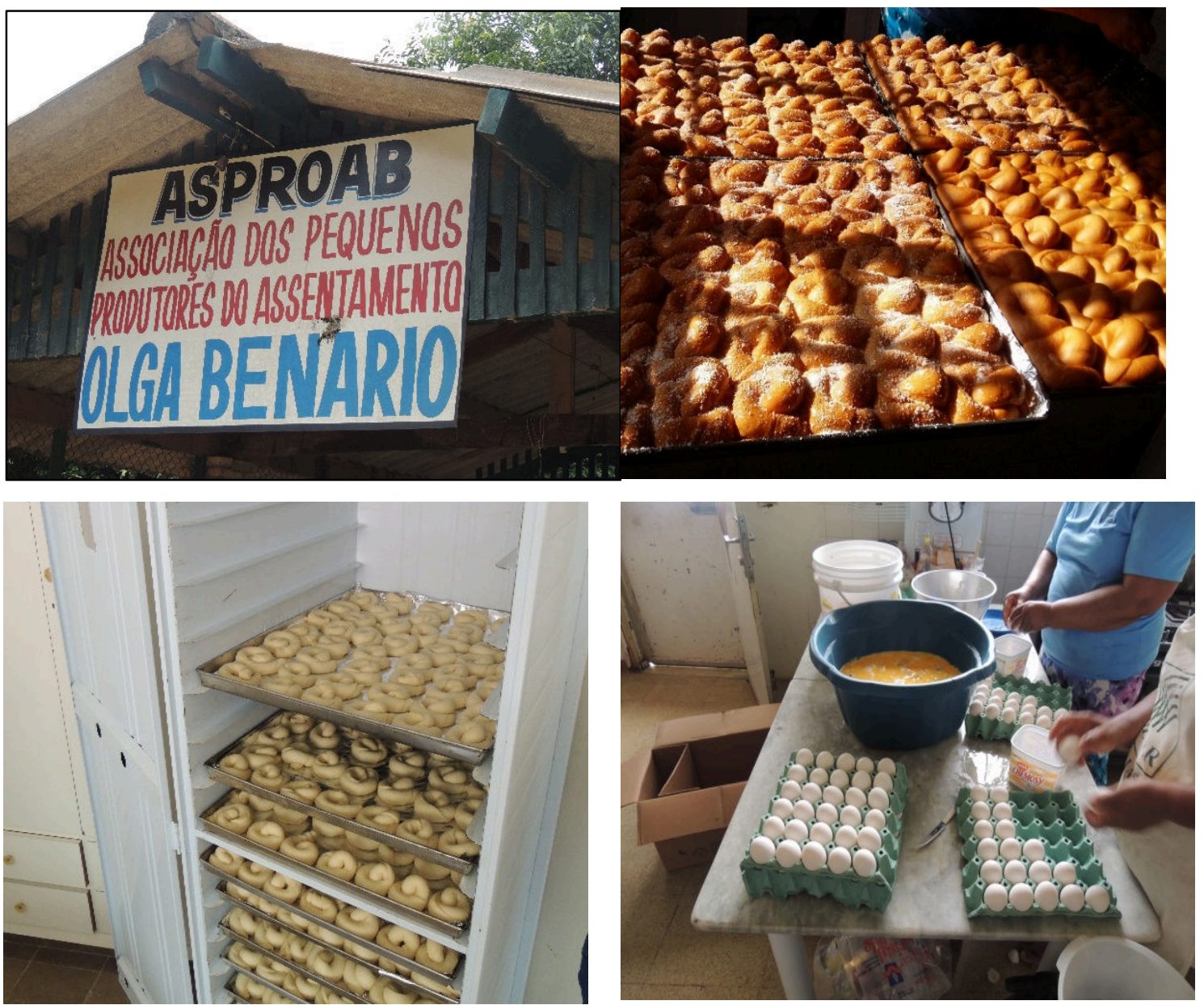

Autora: K. de P Silva. 2016.

No que concerne a ASCRAF, a associação foi criada em 2010 por um grupo de mulheres que visavam trabalhar de forma independente, sendo presidida por uma mulher. No período de realização da visita, possuía 63 associados, sendo 48\% de participação efetiva de mulheres.

$\mathrm{Na}$ associação são produzidos panificados e derivados como bolo, pão, rosca, pão de queijo, biscoito de queijo, tendo todo o processo de trabalho conduzido por trabalho coletivo. Os associados já participaram de vários cursos, com vistas a melhoria na qualidade da produção. Diferentemente da ASBROAB, na ASCRAF há também a participação na entrega de alimentos para o PNAE. Segundo as palavras da presidente “[...] não encontro dificuldades no âmbito da aprovação do projeto, desde que a documentação esteja correta, não existe dificuldade". 
Políticas públicas e desenvolvimento rural em Goiás:

Karinne de Pina Silva análise a partir do Programa de Aquisição de Alimentos (PAA) e do Programa Nacional de Produção e Uso do Biodiesel (PNPB)

É possível perceber a partir da entrevista com a presidente, que se trata de uma experiência de gestão consolidada e ampla legitimidade de influência entre os membros da associação, procurando sempre buscar direitos e benefícios com vistas ao aperfeiçoamento da produção seja da panificadora ou da pequena fábrica de linguiça que está funcionando desde 2014.

Figura 4: Imagens das instalações da panificadora e da fábrica de linguiça da ASCRAF no Assentamento Olga Benário, município de Ipameri-GO.
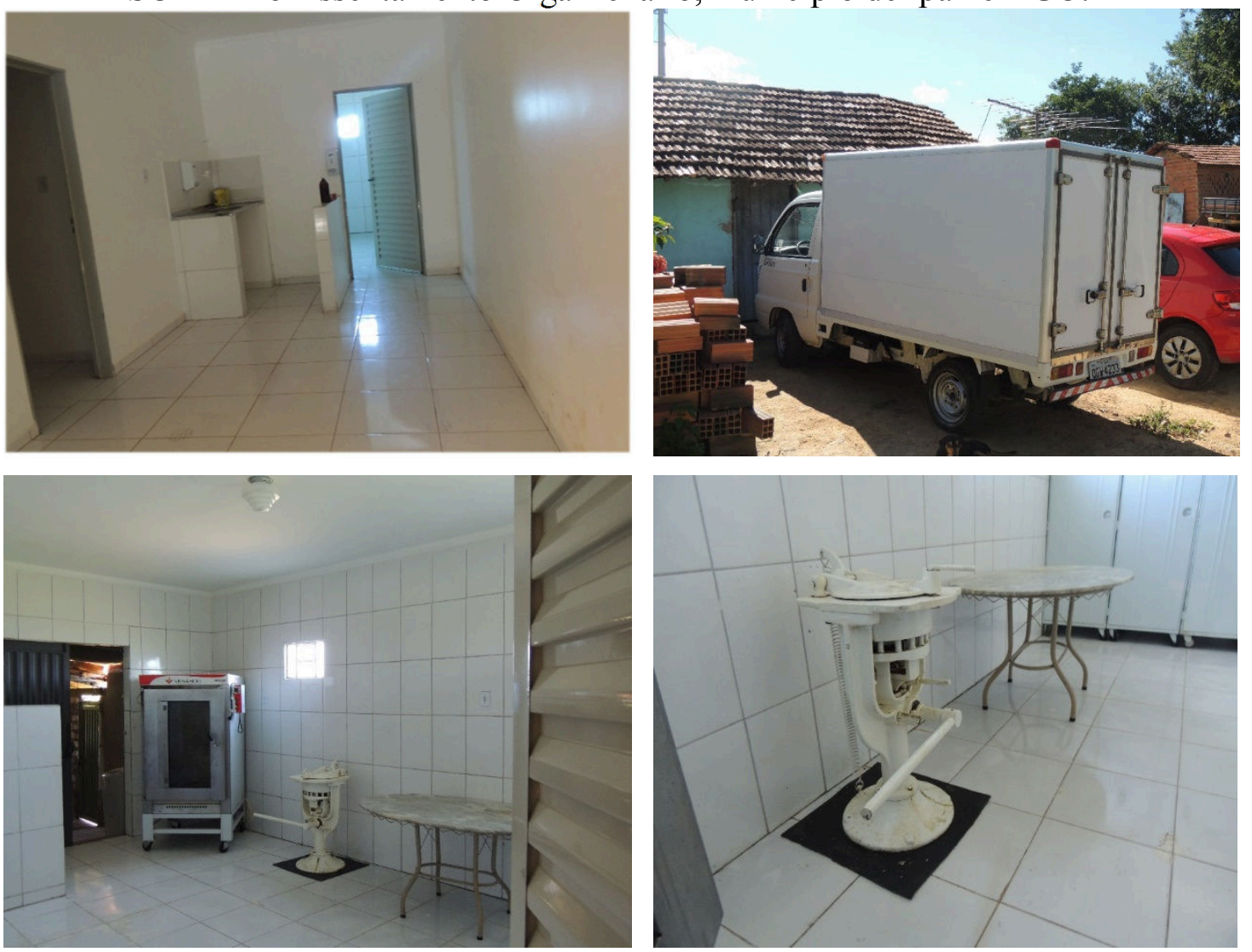

Fonte: K. de P Silva, 2016.

Em 2013 através de um edital ${ }^{7}$ da CONAB, em parceria com o Banco Nacional de Desenvolvimento Social (BNDES) a ASCRAF adquiriu um veículo novo, um forno industrial, um armário, uma batedeira, um amassador entre outros itens para operacionalizar as atividades da panificadora. Assim possuem dois carros, sendo um para os panificados e outro para as carnes e linguiças. Os panificados são entregues semanalmente e os produtos de origem animal, mensalmente. A associação fez um contrato com um abatedouro em Ipameri, que recolhe os frangos e suínos no assentamento 
Políticas públicas e desenvolvimento rural em Goiás:

e realiza o transporte até as entidades beneficiadas. Para isto, é pago ao abatedouro o valor de $\mathrm{R}$ 2,80/frango e R \$/suíno beneficiado/preparado para o consumidor final.

As imagens da panificadora, bem como como os equipamentos para o processamento de linguiça da ASCRAF, podem ser visualizadas na figura 4.

Durante a pesquisa de campo, foi possível averiguar a satisfação com o PAA, pois para os associados, por meio do programa foi possível aumentar a renda obtida o que tem redundado na melhoria da qualidade de vida cotidiana e, por conseguinte, a possibilidade de permanência no campo.

Do ponto de vista das entidades beneficiadas pelo PAA, pode ser evidenciado o êxito na qualidade e diversidade dos alimentos recebidos. Segundo relatos dos diretores de duas escolas de Ipameri, sendo uma municipal e outra estadual, os produtos recebidos auxiliam na complementação da merenda escolar, pois o recurso repassado para as escolas manterem a merenda chega a ser insuficiente perante a demanda e as necessidades nutricionais.

\section{Aspectos do Programa Nacional de Produção e Uso do Biodiesel (PNPB)}

De acordo com os dados oficiais disponibilizados na cartilha do Programa Nacional de produção e uso do Biodiesel (PNPB), o programa surgiu por meio de um decreto da Presidência da República que instituiu um Grupo de Trabalho Interministerial encarregado de apresentar estudos sobre a viabilidade da utilização do biodiesel como fonte alternativa de energia no país. Sendo assim o PNPB é um programa que foi criado em 2004, voltado para a introdução da cadeia de produção do Biodiesel no Brasil, salientando que o Biodiesel é um combustível biodegradável oriundo de fontes renováveis como óleos vegetais, gordura animal. No brasil encontram-se diferentes variedades de oleaginosas como dendê, mamona, girassol entre outros que se produz o biodiesel.

O PNPB Possui três principais diretrizes: promover inclusão social através da geração de renda e emprego; garantir preços competitivos, qualidade e suprimento e a produção do biodiesel a partir de diferentes fontes oleaginosas. Silva (2013) elenca os principais objetivos do Programa:

O programa tem por objetivo principal a implementação da cadeia de produção do biodiesel no Brasil, com a finalidade de reduzir as importações de diesel, reduzir a emissão de poluentes, aumentar a 
competitividade e qualidade do biodiesel brasileiro, e aumentar a diversificação das oleaginosas utilizadas na produção desse biocombustível. (p.18).

O Ministério do Desenvolvimento Agrário (MDA) é responsável por projetar e operacionalizar a estratégia social do PNPB. Dessa forma criou o selo combustível social que é uma forma de identificação concedida pelo MDA para produtores de biodiesel que cumprem os critérios estabelecidos pelo Programa, favorecendo a inclusão social dos agricultores familiares.

Analisando a cartilha oficial do Biodiesel é possível identificar algumas vantagens que o programa PNPB oferece aos produtores do Biodiesel, destacando as seguintes:

Diferenciação/isenção nos tributos PIS/PASEP e COFINS; Participação
assegurada de $80 \%$ do biodiesel negociado nos leilóes públicos da Agência
Nacional do Petróleo, Gás Natural e Biocombustíveis (ANP); Acesso às
melhores condições de financiamento junto aos bancos que operam o
Programa (ou outras instituições financeiras que possuam condições especiais
de financiamento para projetos); Possibilidade de uso do Selo Combustível
Social para promover sua imagem no mercado.

Este programa proporciona uma junção entre Estado, agricultores, cooperativas e empresas privadas. O Estado propicia incentivos fiscais às empresas que adquirem produtos de agricultores familiares, conferindo a estas empresas o selo combustível social, sendo que àquelas empresas que compram uma cota mínima da agricultura familiar, podem participar de leilões organizados pela Agência Nacional do Petróleo, Gás Natural e Bicombustível (ANP).

Apesar de ser um programa que aparenta ser inovador por proporcionar a junção entre Estado, agricultores, cooperativas e empresas privadas, possui entraves como a falta de informações e diminuição da autonomia na produção por parte do agricultor. Também cabe ressaltar a falta de diversidade de matérias-primas, que não atende as demandas do próprio programa, que estão ancoradas justamente na diversidade produtiva para incentivar as potencialidades regionais da agricultura camponesa.

O PNPB começa a funcionar somente em 2008 em Goiás. Segundo informações do MDA o programa tem sido operacionalizado no estado principalmente a partir da produção de soja, que, via de regra, é produzida em grande escala, e portanto, por agricultores não familiares. Face à dimensão produtiva ancorada na produção de soja, é demandada uma grande capitalização dos agricultores. Neste caso, para que a agricultura camponesa se insira neste programa a organização coletiva em cooperativas e/ou 
Políticas públicas e desenvolvimento rural em Goiás:

Karinne de Pina Silva análise a partir do Programa de Aquisição de Alimentos (PAA) e do Programa Nacional de Produção e Uso do Biodiesel (PNPB)

associações é uma condição sine qua non para se adequar ao processo produtivo da matéria-prima.

Na tabela 2, são apresentados os dados com a evolução do número de famílias fornecedoras de matéria-prima nos arranjos do Selo Combustível Social, bem como as bem como as cooperativas, volume alocado de matéria-prima e o valor:

Tabela 2: Dados do Selo Combustível Social - PNPB em Goiás - 2008 a 2017

\begin{tabular}{c|c|c|c|c}
\hline \multirow{2}{*}{ Ano } & $\mathbf{N}^{\mathbf{0}}$ de Famílias & $\begin{array}{c}\mathbf{N}^{\mathbf{0}} \text { de } \\
\text { Cooperativas }\end{array}$ & $\begin{array}{c}\text { Volume de } \\
\text { matéria prima } \\
\text { (mil toneladas) }\end{array}$ & $\begin{array}{c}\text { Valor } \\
\text { (milhões R\$) }\end{array}$ \\
\hline $\mathbf{2 0 0 8}$ & 945 & 1 & 71,26 & 73,94 \\
\hline $\mathbf{2 0 0 9}$ & 1.094 & 2 & 175,19 & 133,11 \\
\hline $\mathbf{2 0 1 0}$ & 1.672 & 2 & 247,96 & 148,45 \\
\hline $\mathbf{2 0 1 1}$ & 1.819 & 4 & 243,81 & 181,49 \\
\hline $\mathbf{2 0 1 2}$ & 2.066 & 9 & 309,44 & 251,92 \\
\hline $\mathbf{2 0 1 3}$ & 2.249 & 10 & 315,73 & 290,83 \\
\hline $\mathbf{2 0 1 4}$ & 1.970 & 9 & 293,71 & 299,96 \\
\hline $\mathbf{2 0 1 5}$ & 1.887 & 7 & 297,87 & 300,35 \\
\hline $\mathbf{2 0 1 6}$ & 1.730 & 6 & 292,13 & 336,08 \\
\hline $\mathbf{2 0 1 7}$ & 1.231 & 5 & 207,48 & 234,73 \\
\hline
\end{tabular}

Fonte: SIC-SAF/MDA. Adaptado: SILVA, K.P., 2019.

Os dados comprovam as informações fornecidas pelo MDA de que o PNPB é um programa que exerce uma grande capitalização. Ao analisarmos os dados podemos averiguar que é positiva a quantidade de evolução das famílias fornecedoras com o valor adquirido com a matéria prima fornecida.

É possível destacar que por mais que o PNPB seja um programa que foi feito para a inserção da agricultura familiar no mercado, pressupondo a valorização da diversificação dos produtos de origem familiar, apenas uma oleaginosa possui predominância na produção no estado de Goiás, que é a soja.

Podemos observar esse destaque na tabela 3:

Tabela 3: Tipo de matéria-prima utilizada pelo PNPB na região Centro-Oeste em 2014 e $2018 *$

\begin{tabular}{l|c|c}
\hline Matéria Prima & $\mathbf{2 0 1 4}(\mathbf{e m ~ \% )}$ & $\mathbf{2 0 1 8} \mathbf{~ e m ~ \% ~}$ \\
\hline Óleo de Soja & 84,44 & 81,40 \\
\hline Gordura Bovina & 12,24 & 6,50 \\
\hline Óleo de Algodão & 1,75 & 1,80 \\
\hline Outros Materiais Graxos & 0,46 & 8,00 \\
\hline Óleo de Fritura Usado & 1,00 & 0,10 \\
\hline Gordura do Porco & 0,03 & 0,20 \\
\hline Outros & 0,08 & 2,00 \\
\hline
\end{tabular}

Fonte: Boletim mensal - Agência Nacional do Petróleo, Gás Natural e Biocombustíveis (ANP). *Os dados se referem aos meses de dezembro de cada ano selecionado. Org.: OLIVEIRA, Adriano R. de, 2019. 
Políticas públicas e desenvolvimento rural em Goiás:

$\mathrm{Na}$ tabela 3, observamos o percentual das matérias-primas utilizadas para a produção de biodiesel na região Centro-Oeste nos anos de 2014 e 2018. É nítida a discrepância da soja enquanto matéria-prima hegemônica em relação aos outros tipos de materiais utilizados para a produção do biodiesel. Esse cenário se repete quando averiguamos os dados na escala nacional: em 2018 a soja equivaleu a 67,8\% da matériaprima responsável pela produção de biodiesel na Agência Nacional de Petróleo.

Para que os produtores de biodiesel se beneficiem dos privilégios já discutidos anteriormente, precisam seguir algumas regras, cumprir algumas tarefas para com o agricultor familiar, que são esclarecidas na cartilha oficial do PNPB (2010):

- Firmar contratos com os agricultores familiares negociados com a participação de uma entidade representativa dos mesmos (sindicatos, federações). A agricultura familiar organizada na forma de sindicatos ou federações terá que dar anuência por meio de carta para validar o que foi acordado entre as partes;

- Repassar cópia dos contratos devidamente assinados pelas partes para o agricultor familiar contratado e para a entidade representativa (sindicato, federação, outros)

- Assegurar assistência técnica gratuita aos agricultores familiares contratados: Capacitar os agricultores e agricultoras familiares para a produção de oleaginosa(s), de forma compatível com a segurança alimentar da família e com os processos de geração de renda em curso, contribuindo para a melhor inserção da agricultura familiar na cadeia produtiva do biodiesel e para o alcance da sustentabilidade da propriedade

- Repassar ao agricultor familiar assistido pelo técnico, cópia do laudo de visita devidamente assinado;

- Adquirir um percentual mínimo de matéria prima da agricultura familiar, que varia de região para região, de acordo com a normativa vigente.

A análise detalhada dos desdobramentos do PNPB em Goiás requer aprofundamento em outras pesquisas. Contudo, é possível destacar que o PNPB é um programa essencialmente voltado à integração do agricultor à indústria por meio da subordinação de sua renda da terra ao capital por meio dos contratos de parcerias estabelecidos pelas cooperativas e associações. 


\section{Considerações finais}

É possível afirmar que os dois programas analisados na presente pesquisa - PAA e PNPB - se diferem desde a concepção e ambos representam uma nova perspectiva em referência às políticas de desenvolvimento rural, que passam de um viés setorial e produtivista e passa a colocar produção camponesa como foco, ainda que sob prismas distintos.

Sabe-se que àquele produtor que antes detinha autonomia em sua produção, que não se submetia essencialmente ao consumo de insumos, porque produzia apenas para o autoconsumo ou para uma pequena clientela, agora, por meio das políticas públicas que visam a sua inserção ao mercado, podem ter os seus saberes e fazeres desconstituídos dependendo do formato em que são gestadas essas políticas.

Durante a pesquisa de campo com os agricultores que estão inseridos nessas políticas que visam a inserção ao mercado, foi possível perceber uma necessidade de se adequar a produção pensada em alta escala, partindo do pressuposto que essa produção é uma característica dos grandes produtores rurais, que como salientado no decorrer do artigo foram os possuidores dos privilégios e do mercado por um longo tempo.

A partir da pesquisa feita em fontes secundárias e primárias por meio do campo realizado no Município de Ipameri- GO, foi possível destacar a importância dos programas para desenvolvimento local e regional, destacando principalmente o programa PAA que é um programa que além de ser importante para o desenvolvimento da agricultura camponesa como é posto na cartilha do PAA, ele também propicia uma segurança alimentar para aqueles que são beneficiados com os produtos que advém da agricultura familiar.

O PNPB confirma o aspecto das políticas públicas que visa o caráter setorial, que submete os agricultores camponeses ao modelo produtivista, sem considerar seu modo de vida e seus saberes. O programa de fato não responde suas próprias demandas e objetivos, como utilização da diversificação das matérias-primas, permanecendo a soja como matéria prima mais utilizada.

Os programas precisam se adequar a realidade dos sujeitos que são inseridos e não o contrário. É preciso também facilitar desde a organização dos documentos para participar das políticas públicas à sua execução, ou seja, diminuir a burocracia que tem se destacado nas reclamações dos camponeses para acessar aos programas. 
Políticas públicas e desenvolvimento rural em Goiás: análise a partir do Programa de Aquisição de Alimentos (PAA) e do Programa Nacional de Produção e Uso do Biodiesel (PNPB)

Além disso, mais do que a inserção produtiva ao mercado, é fundamental que se valorize as características produtivas da agricultura camponesa. O PAA possui perspectivas favoráveis, pois apesar de seus limites de abrangência tem incentivado a diversidade produtiva, pois está ancorado na produção de alimentos com vistas à Segurança Alimentar e Nutricional.

O PNPB, por sua vez, por estar pautado majoritariamente na soja como matériaprima para a produção de biodiesel, tem retroalimentado a especialização produtiva e pela natureza do programa, acaba ampliando a subordinação da agricultura à indústria, pois a ANP e Petrobrás, realizam a aquisição do óleo bruto e não da matéria-prima in natura. Tal cenário inviabiliza de imediato a inserção da produção em pequena escala, em virtude do alto índice de capitalização requerido para o processamento das matérias-primas e sua conversão em óleo.

Isto posto, os programas caminham por percursos distintos. Por um lado, o PAA, que possui como horizonte a diversificação produtiva, a produção de comida e a Segurança Alimentar e Nutricional. Por outro lado, o PNPB, que está focado na especialização produtiva e na produção de combustível. Resta saber, qual é o caminho mais efetivo para um desenvolvimento rural estrutural e efetivo.

\section{Notas}

\footnotetext{
${ }^{1}$ Pesquisa inserida no projeto de pesquisa intitulado "Políticas Públicas de Desenvolvimento Rural em Goiás: uma análise do PAA e do PNPB” com financiamento da Chamada Universal MCTI/CNPq 14/2014.

2 Em função da interrupção do mandato da presidenta Dilma Rousseff em 2016, o Ministério de Desenvolvimento Agrário perdeu o status de ministério e se converteu em Secretaria da Agricultura Familiar e Desenvolvimento Agrário vinculada à Casa Civil do Governo Federal.
}

3 “O PNAE é o mais antigo programa do governo brasileiro na área de alimentação escolar e de Segurança Alimentar e Nutricional (SAN), sendo considerado um dos maiores e mais abrangentes do mundo no que se refere ao atendimento universal aos escolares e de garantia do direito humano à alimentação adequada e saudável". (BRASIL, 2015, p. 9)

${ }^{4}$ A Declaração de Aptidão ao Pronaf (DAP) é o documento de identificação do agricultor familiar e pode ser obtido tanto pelo agricultor (pessoa física) quanto por empreendimentos familiares rurais, como associações, cooperativas, agroindústrias (pessoa jurídica).

${ }^{5}$ Segundo a regionalização do IBGE, a microrregião geografia de Catalão é formada por 11 municípios: Anhanguera, Campo Alegre de Goiás, Catalão, Corumbaíba, Cumari, Davinópolis, Goiandira, Ipameri, Nova Aurora, Ouvidor e Três Ranchos.

${ }^{6}$ TERRA SOL é um programa do INCRA de fomento à agroindustrialização e à comercialização por meio da elaboração de planos de negócios, pesquisa de mercado, consultorias, capacitação em viabilidade econômica, além de gestão e implantação/recuperação/ampliação de agroindústrias. Atividades não agrícolas - como turismo rural, artesanato e agroecologia - também são apoiadas. 
${ }^{7}$ A CONAB, em parceria com o Banco Nacional de Desenvolvimento Social (BNDES) firmou a primeira chamada pública em 2013, com o objetivo de selecionar e apoiar projetos que contribuam para o fortalecimento social e econômico das organizações produtivas rurais de base familiar que fornecem alimentos para o PAA. Iniciativa destinada a solucionar os gargalos operacionais das organizações produtivas que a pequeno e médio prazo melhorará a qualidade e a quantidade de alimentos produzidos e desembocará em benefícios imediatos para a população inserida na situação de insegurança alimentar. Esta parceria se estendeu para o ano de 2014 onde foi formalizado o $2^{\circ}$ edital. (CONAB).

\section{Referências}

BIACHINI, Valter. Políticas diferenciadas para a agricultura familiar. Revista Conjuntura Econômica. v. 59, n. 5 2005. Disponível em: -

$>$ http://bibliotecadigital.fgv.br/ojs/index.php/rce/article/view/27880/26755> Acesso em: 10 de maio de 2016.

BRASIL, Presidência da República. Lei no 10.696, de 2 de julho de 2003. Disponível em: $<$ http://www.planalto.gov.br/ccivil_03/leis/2003/110.696.htm>. Acesso em: $12 \mathrm{de}$ março de 2015.

BRASIL, Ministério da Educação (Fundo Nacional de Desenvolvimento da Educação FNDE). Cartilha Nacional de Alimentação Escolar. 2a edição. Brasília, 2015.

BRASIL, Presidência da República. Lei 11.947 de 16 de junho de 2009. Disponível em: <http://www.planalto.gov.br/ccivil_03/_ato2007-2010/2009/lei/111947.htm.> Acesso em: 20 de Maio 2016.

BRASIL. Ministério do Desenvolvimento Agrário. Cartilha do Programa Nacional de Produção e Uso do Biodiesel. Disponível em:

http://www.mda.gov.br/sitemda/sites/sitemda/files/user_arquivos_64/Biodiesel_Book_fi nal_Low_Completo.pdf> Acesso em: 10 de Janeiro de 2016.

BRASIL. Ministério do Desenvolvimento Agrário. Programa de Aquisição de Alimentos - Cartilha PAA. 2012. Disponível em: <

http://www.mda.gov.br/sitemda/sites/sitemda/files/user_arquivos_64/CARTILHA_PAA _FINAL.pdf> Acesso em: 20 de Novembro de 2015.

BRASIL. Agência Nacional do Petróleo, Gás Natural e Bicombustíveis (ANP). Boletim mensal do Biodiesel. Disponível em:

http://www.anp.gov.br/?pg=82402\&m=\&t1 =\&t2=\&t3=\&t4=\&ar=\&ps=\&14705734311 67 Acesso em: 20 de Junho de 2016.

BRASIL. Ministério da Agricultura, Pecuária e Abastecimento. Disponível em: http://www.mda.gov.br/sitemda/secretaria/saf-biodiesel/o-selo-combust\%C3\%ADvelsocial. Acessoem 24 de Janeiro de 2019.

DATALUTA. Banco de Dados da Luta Pela Terra. Presidente Prudente: FCT/UNESP, 2015. 
DELGADO, Nelson Giordano. As relações entre a macroeconomia e a política agrícola. Provocações para um debate interrompido. In: Estudos Sociedade e Agricultura, 14, outubro 1999:173-180.Disponivel em:<http://r1.ufrrj.br/esa/V2/ojs/index.php/esa/article/viewFile/172/168 Acesso em: 05 de março de 2016.

FERNANDES, Bernardo Mançano. Conflitualidade e desenvolvimento territorial: questão agrária. Disponível em <

http://bibspi.planejamento.gov.br/bitstream/handle/iditem/564/Quest $\% \mathrm{C} 3 \% \mathrm{~A} 30 \% 20 \mathrm{agr}$ $\% \mathrm{C} 3 \%$ A1ria_conflitualidade $\% 20 \mathrm{e} \% 20 \mathrm{desenvolvimento} \% 20$ territorial.pdf? sequence $=1$ $>$ Acesso em 10 de maio de 2016.

GONÇALVES, Daniel Bertoli. Os desafios da agricultura familiar frente aos programas de compras públicas de alimentos: um estudo sobre agricultores da região sudoeste do estado de São Paulo. Disponível em:

http://revistas.unincor.br/index.php/revistaunincor/article/view/1413. Acesso em: 16 de abril de 2016.

HESPANHOL, Antonio Nivaldo. Políticas Públicas, modernização e crise da agricultura brasileira. Revista Faz Ciência. v.1, n.1, p.38-49: Faculdade de Francisco Beltrão, 1997. Disponível em: <http://erevista.unioeste.br/index.php/fazciencia/article/view/7624/5614>. Acesso em: 19 maio 2013.

IBGE. Censo Agropecuário. Resultados Preliminares. 2017. Disponível em https://censos.ibge.gov.br/agro/2017/resultados-censo-agro-2017.html

JORNAL BRASIL DE FATO. PR: Agricultores presos por ordem de Sérgio Moro são inocentados. Curitiba: PR, 05 de outubro de 2017. Disponível em: https://www.brasildefato.com.br/2017/10/05/pr-agricultores-presos-por-ordem-desergio-moro-sao-inocentados/. Acesso em 31 de março de 2019.

SECCHI, Leonardo. Políticas Públicas: Conceitos, Esquemas de análises, Casos Práticos. São Paulo: Cengage Learning, 2010.

SILVA, J. A. Avaliação do Programa Nacional de Produção e Uso do Biodiesel no Brasil - PNPB. Revista de Política Agrícola. Ano XXII - No 3 - Jul./Ago./Set. 2013. Disponível em: http://ainfo.cnptia.embrapa.br/digital/bitstream/item/92833/1/Avaliacaodo-programa-nacional-de-producao-e-uso-do-biodiesel.pdf. Acesso em: 21 jun. de 2016.

SOUZA, Rodrigo Gonçalves de. Alcance de políticas públicas federais no cooperativismo da Agricultura familiar em goiás do ano de 2007 ao ano de 2014 fragilidades e potencialidades. Tese [Mestrado em Agronegócio]. Goiânia: UFG/PPAgro, 2016. 
OLIVEIRA, Adriano Rodrigues de. O associativismo na região do Pontal do

Paranapanema-SP: limites e possibilidades para o desenvolvimento rural. 2010. $209 \mathrm{f}$. Tese (Doutorado em Geografia) - Faculdade de Ciências e Tecnologia, Universidade Estadual Paulista, Presidente Prudente, 2010.

PEIXOTO, Ângela Maria M. As políticas públicas de desenvolvimento rural em Goiás: os efeitos do PAA e do PNPB para a agricultura camponesa. Tese. [Mestrado em Geografia]. Goiânia: UFG/PPGeo, 2016.

RIBEIRO, Dinalva Donizete; DIAS, Mariza Souza. Políticas públicas para a agricultura familiar: o PAA e o PNPB. Mercator, Fortaleza, v. 12, n. 27, p.81-91, jan./abr. 2013. Disponível em: <http://www.mercator.ufc.br/index.php/mercator/article/view/743/465>. Acesso em: 03 set. 2013.

TEIXEIRA, E. C. Políticas públicas: O papel das políticas públicas. Revista AATRBA, 2002. Disponivel em: $<$ www.escoladebicicleta.com.br/politicaspublicas.pdf $>$ Acesso em: 18 de Abril de 2016.

Recebido em 20/02/2018.

Aceito para publicação em 12/09/2018. 